\begin{tabular}{|c|l|}
\hline Title & Low cycle thermal fatigue and microstructural change of A C2B-T6 al uminum alloy \\
\hline Author(s) & Sasaki, Katsuhiko; Takahashi, T suyoshi \\
\hline Citation & $\begin{array}{l}\text { International Journal of Fatigue, 28(3), 203-210 } \\
\text { https://doi.org/10.1016/.ijfatigue.2005.06.025 }\end{array}$ \\
\hline Issue Date & 2005-08-02 \\
\hline Doc URL & http://hdl.handle.net/2115/1399 \\
\hline Type & article (author version) \\
\hline File Information & IJF28 3.pdf \\
\hline
\end{tabular}

Instructions for use 


\title{
Low Cycle Thermal Fatigue and Microstructural Change of AC2B-T6 Aluminum Alloy
}

\author{
Katsuhiko SASAKI \\ Division of Mechanical Science, Hokkaido University, \\ N13, W8, Kita-ku, Sapporo, 060-8628 Japan \\ TEL:+81-11-706-6415, FAX:+81-11-706-7889 \\ E-mail: katsu@eng.hokudai.ac.jp \\ (Corresponding Author) \\ Tsuyoshi TAKAHASAHI \\ Department of CAE \& System Promotion, Hokkaido Engineering Group, \\ ISUZU Motors Limited, Chitose, 066-0009 Japan
}

\begin{abstract}
Low cycle thermal fatigue tests were conducted using an aluminum alloy AC2B-T6, which is widely used in diesel engines, especially, in cylinder heads. Specimens made of the AC2B-T6 alloy were subjected to thermal fatigue with thermo-mechanical loadings over several temperature ranges, symmetric and asymmetric strain amplitudes, and cycle periods. These test conditions are chosen considering realistic running conditions of diesel engines. A method to predict time to fatigue failure under the test conditions is proposed. The specimens were also observed by transmission electron microscope (TEM) to clarify the effects of temperature, strain amplitude, and cycle period on microstructural changes such as precipitates. Finally, the relationship between the microstructural changes and the low cycle thermal fatigue is discussed.
\end{abstract}

Key Words: Low Cycle Thermal Fatigue, Aluminum Alloy, Precipitate, Plasticity, Engines 


\section{INTRODUCTION}

Demand for an aluminum alloy cylinder head for diesel engines has increased to reduce

the weight of automobiles and improve fuel economy for environmental protection. However, low durability of aluminum alloys as a result of low cycle fatigue failure at high temperatures is an important issue in predicting efficient engine systems where the cylinder head can be used at higher temperature than in existing engine systems.

The cylinder head is subjected to heat cycling, i.e. the temperature of an engine is low at stopping and high when running. As a result, aluminum alloys used for cylinder heads are subjected to thermo-mechanical loading, which causes thermal fatigue failure. Aluminum alloys are usually hardened by precipitation, and the microstructure of the aluminum alloys change due to the high temperature at running [1]. Non-linear mechanical behaviors such as plastic and viscoplastic deformation caused by thermo-mechanical loading also lead to microstructural changes [1]. Therefore, evaluation of low cycle thermal fatigue failure is very difficult. This suggests the need for a new method to evaluate thermal fatigue failure. Also, the microstructural changes due to thermo-mechanical loading must be better understood to help in the development of new aluminum alloys for more reliable cylinder heads.

Fatigue and fracture toughness of high-strength aluminum alloys have been studied extensively. Srivatsan et al. [2] studied the influence of temperature on cyclic stress response 
characteristics, cyclic strain resistance, fatigue life, and fracture behavior of the AA2254 aluminum alloy and they observed the microstructural changes during the loading. Clark et al. [3] conducted fatigue tests using the AA7050-T7351 aluminum alloy and examined temperature effects on fatigue failure. DeBartolo et al. [4] studied fatigue behavior of an aluminum alloy containing particle clusters and established the effect of constituent particles on the fatigue failure. Yu et al. [5] investigated hardness, strength, and elongation using the AA2618 aluminum alloy with $\mathrm{Al}_{3}(\mathrm{Sc}, \mathrm{Zr})$ phases at several temperatures. Fujii et al. [6] investigated the microstructural evolution during fatigue under constant stress amplitudes using a polycrystalline AA3003 aluminum alloy, and compared the results with the stress-strain responses under constant strain amplitudes. Bergsma et al. [7] studied the effect of temperature on strength and fatigue resistance of the AA6069 aluminum alloy from microscopic observations. Turkmen et al. [8] examined the uniaxial cyclic response of an aluminum alloy, AA7075-T6, based on finite element (FEM) simulation considering microstructural changes and compared the simulation with the macroscopic behavior obtained by tests. Fan et al. [9] performed a FEM analysis for micronotches including pores and silicon particles of an AA356 aluminum alloy to better understand the fatigue resistance from a microscopic point of view.

The effects of heat treatments and ambient temperature on mechanical properties and fatigue failure of aluminum alloys have also been studied. Tsai et al. [10] observed the microstructure of tensile test specimens and concluded that an over-aging treatment is effective to 
prevent stress corrosion cracking at room temperature. Esmaeili et al. [11] examined the deformation behavior of AA6111 as a function of temperature and precipitates using work hardening behavior analysis and strain rate sensitivity measurements. Dumont et al. [12] investigated the relationship between yield strength, strain hardening, notch resistance, and fracture and microstructural changes such as precipitates using the AA7050 aluminum alloy.

In these studies, however, the microstructural characteristics such as precipitates and dislocation densities were not evaluated quantitatively, and very few thermal fatigue tests of aluminum alloys for engine parts have been conducted under actual engine running conditions [13]. Recently, the authors conducted FEM analysis of a cylinder head considering the microstructure distribution due to casting conditions [14].

In this paper, a method to evaluate low cycle thermal fatigue failure, and microstructure changes during the thermal fatigue failure was studied using an AC2B-T6 aluminum alloy for cylinder heads. First, low cycle thermal fatigue tests were performed under engine running conditions to clarify the elastic, plastic, viscoplastic deformation, and thermal fatigue failure. An efficient method to evaluate the low cycle thermal fatigue failure was developed to estimate the fatigue failure due to different temperature ranges, symmetric and asymmetric strain ranges, and cycle periods. Microstructural changes after low cycle thermal fatigue tests were observed by TEM, especially focusing on precipitates. The relationship between precipitates and temperature range, 
symmetric strain ranges, and cycle periods during the low cycle thermal fatigue tests are discussed.

\section{EXPERIMENTAL PROCEDURES}

\subsection{Specimens and Testing Machine}

Table 1 shows the chemical composition of the tested alloy. The alloy is AC2B treated by the T6 heat treatment. The alloy was held at $490^{\circ} \mathrm{C}$ for 1.5 hours, then quenched in water, and artificially aged at $196{ }^{\circ} \mathrm{C}$ for 2 hours. The dendrite Arm Spacing (DAS) was 0.02 to $0.03 \mathrm{~mm}$ and the volume fraction of porosity smaller than $0.3 \%$. Test pieces for the low cycle thermal fatigue tests were solid rods which have a diameter of $7 \mathrm{~mm}$ and gauge length of $21 \mathrm{~mm}$, respectively.

The specimens for the microscopic observations were sampled approximately $3 \mathrm{~mm}$ from the fractured surface of the test piece in the longitudinal direction; the specimens were circular plates which have a $2 \mathrm{~mm}$ diameter and $0.2 \mathrm{~mm}$ thick, respectively. The center of the circular plate was thinned by electrolytic polishing using methanol nitrite. The minimum thickness of the sample was around 500nm. The microstructure was observed by a transmission electron microscope (TEM) of $200 \mathrm{kV}$ accelerating voltage. The same crystal plane was observed in the same direction for all the samples: $<110>$, $g=\{111\}$.

An electro-hydraulic servo testing machine, MTS 810, was used for the thermal fatigue tests. Strain was measured by using an extensometer, the MTS model 632, 50C-05 [13]. The test 
pieces were heated by an induction heating apparatus, Shimada-Rika SST-20L. The specimens were cooled down by air blowing with controlling air to keep the temperature error under 0.2K. FEM analyses were conducted to clarify the temperature distribution of the specimen during the heating and cooling processes. The maximum difference in the temperature between the surface and center of the specimen was $0.2 \mathrm{~K}$. Therefore the temperature distribution of the specimen does not affect on the test results significantly.

\subsection{Test Method and Conditions}

Figure 1 shows the strain and temperature conditions in the thermal fatigue tests. The waves of both strain and temperature are triangular, and controlled so that the maximum strain is produced at the lower temperature, to simulate actual running conditions in engines.

Table 2 shows the test conditions. The test parameters are the total strain amplitude $\Delta \varepsilon$, temperature range $\Delta T$, and cycle time $\Delta t$, each at two or more values; $\mathrm{N}_{\mathrm{f}}$ is the number of cycles to fatigue failure, which was defined as the number of cycles when the tensile load was reduced to $75 \%$ of the maximum or steady-state value, and $t_{\mathrm{f}}$ is the time to fatigue failure.

Tests No.9 11 were conducted in the asymmetric strain range, where the center of the strain was not zero, and they are referred to as 'mean strain tests' hereafter. These test conditions were chosen to simulate the running conditions of the engine $[15,16]$.

In all the thermal fatigue tests, loading was started in the compressive direction, as in a 
real engine [15]. The brackets of tests No.3 8 indicate that the microstructural observations were conducted by TEM.

\section{RESULTS OF LOW CYCLE THERMAL FATIGUE TESTS}

\subsection{Stress-Strain Relations Caused by Thermo-Mechanical Loading}

Figure 2 (a) shows stress-strain relations for several temperatures ranges; $100^{\circ} \mathrm{C}$ to $200^{\circ} \mathrm{C}$, $100^{\circ} \mathrm{C}$ to $250^{\circ} \mathrm{C}$, and $120^{\circ} \mathrm{C}$ to $300^{\circ} \mathrm{C}$ with a strain amplitude of $0.55 \%$ under a cycle period of 10 minutes. In Fig. 2 only the 3rd cycle is shown for clarify. The stress-strain relations are very different in the different temperature ranges. Stress relaxation occurred in the compressive process in the $100^{\circ} \mathrm{C}$ to $250^{\circ} \mathrm{C}$ and $120^{\circ} \mathrm{C}$ to $300^{\circ} \mathrm{C}$ temperature ranges. The stress relaxation starts at around $-0.3 \%$ in the $100^{\circ} \mathrm{C}$ to $250^{\circ} \mathrm{C}$ temperature range, and at around $-0.06 \%$ in the $120^{\circ} \mathrm{C}$ to $300^{\circ} \mathrm{C}$ temperature range. Both the total strains of $-0.3 \%$ and $-0.06 \%$ correspond to temperatures of approximately $220^{\circ} \mathrm{C}$. The $220^{\circ} \mathrm{C}$ (493K) temperature is about $56 \%$ of the melting point $\mathrm{T}_{\mathrm{m}}$ of the aluminum alloy, $615^{\circ} \mathrm{C}(888 \mathrm{~K})$. The temperature range between $0.5 \mathrm{~T}_{\mathrm{m}}$ and $0.6 \mathrm{~T}_{\mathrm{m}}$ is considered to be the range where both diffusion creep and dislocation creep occur, and the alloy is considered to soften in this temperature range. At the same time, stress relaxation does not occur in the tensile process where the temperature is low.

Figure 2 (b) shows the stress-strain relation with different cycle period. In Fig. 2 (b), the 
cycle periods differ from 5,10 , to 20 minutes at the strain amplitude of $0.55 \%$ in the $100^{\circ} \mathrm{C}$ to $250^{\circ} \mathrm{C}$

temperature range. There is a small but noticeable difference in maximum stress due to the cycle

period despite the only 4 times difference in cycle period. The minimum stress decreases as the cycle period becomes shorter, and the maximum difference between the 5 and 20 minute cycle periods is about 20MPa.

Figure 2 (c) shows the stress-strain relation at the 3rd cycle of four different mean strain tests. The stresses at the maximum and minimum strains of the three mean strain tests of $-0.15,0.15$, and $-1.55 \%$ are almost the same values, while those of $0 \%$ mean strain test are a little smaller than the others.

\subsection{Method of to Evaluate Low Cycle Thermal Fatigue Failure}

The $\mathrm{N}_{\mathrm{f}}$ and $\mathrm{t}_{\mathrm{f}}$ in Table 2 show the number of cycles and time to fatigue failure. There are large differences in the $\mathrm{N}_{\mathrm{f}}$ and $\mathrm{t}_{\mathrm{f}}$ fatigue lives due to temperature range, cycle period, the strain range, and mean strain. The fatigue life becomes shorter as the strain range becomes larger, and it is longer as the cycle period is lengthens and as the maximum temperature increases. However, the mean strain does not correlate with fatigue life.

In this paper the plastic work density per unit time was used as a parameter in evaluating fatigue failure. Figure 3 shows the definitions of the plastic work density per unit time; the total strain amplitude $\Delta \varepsilon_{3}$, plastic strain amplitude $\Delta \varepsilon_{3}^{p}$, and stress amplitude $\Delta \sigma_{3}$ for the 3rd cycle 
stress-strain curve are also shown in Fig. 3. The plastic work density per unit time $\Delta P_{3}$ can be expressed by the plastic strain energy density $\Delta S_{3}$, which is the area of the stress-stress curve at 3rd cycle, and the cycle period $\Delta t$ as follows:

$$
\Delta P_{3}=\frac{\Delta S_{3}}{\Delta t}
$$

The reason for focusing on the 3rd cycle is that if the parameter of the early stage of the

fatigue process can be used, a great deal of time for computer simulation can be saved in estimating the fatigue life by the structural analysis and thermo-mechanical fatigue test.

Coffin-Manson relation $[17,18]$ has been widely used for evaluations of low cycle fatigue failure. To evaluate fatigue failure under creep-fatigue interaction conditions, the plastic strain energy density has been used [19, 20] and applied to stainless steels [21] and solder alloys [22, 23]. However the plastic strain energy density can not be applied to the thermal fatigue failure of the aluminum alloy because the effect of cycle period on the hysteresis loops is small as shown in Fig. 2(b) though the effect of the cycle period on the number of cycle to fatigue failure is large. In this paper, therefore the plastic work density per unit time was used as a parameter in evaluating fatigue failure.

Figure 4 shows the relationship between the plastic strain amplitude and fatigue life time in log-log scale because the plastic strain amplitude is ordinarily used to evaluate low cycle fatigue failure as the Coffin-Manson relation [17, 18]. The arrow in Fig. 4 shows the results of the mean 
strain tests. The relationship between the plastic strain amplitude and fatigue life time relation is

expressed by using the least squares method as follows:

$$
\Delta \varepsilon_{3}^{p}=0.400 \cdot t_{f}^{-0.0216}
$$

The correlation coefficient of Eq. (2) is the very low value of 0.174 . This low correlation means that the plastic strain amplitude cannot be an appropriate index for estimating the fatigue life considering the thermo-mechanical conditions including various strain amplitudes, temperature ranges, cycle periods, and mean strains.

Figure 5 shows the relationship between the plastic work density per unit time and fatigue life time. The solid line is obtained by the following equation determined by the method of least squares.

$$
\Delta P_{3}=0.0503 \cdot t_{f}^{-0.246}
$$

The correlation coefficient between the two is 0.944 in spite of different test conditions such as strain amplitude, cycle period, temperature range, and mean strain. Consequently, the plastic work density per unit time can be a useful index for evaluating low cycle thermal fatigue life. However it should be noted that the plastic work density per unit time can be used when the effect of cycle period on number to fatigue failure is much larger than that on the hysteresis loop.

\section{MICROSTRUCTURAL CHANGES DUE TO THE THERMAL FATIGUE TESTS}


The aluminum alloy AC2B-T6 is strengthened by both solutions of $\mathrm{Cu}$ and precipitates of metastable medium phases such as $\mathrm{Al}_{2} \mathrm{Cu}$. The precipitation hardening of materials subjected to $\mathrm{T} 6$ heat treatment is the highest in the materials subjected to other heat treatments such as T3, T4, T5, T7, T8, and T9 for aluminum alloys. This means that the precipitates mainly dominate the hardening of the aluminum alloy AC2B-T6. Therefore, if there is a correlation between the low cycle thermal fatigue failure and precipitates, and this correlation could be incorporated into a method to evaluate fatigue failure, the development of new aluminum alloys could proceed more rapidly. Here, the precipitate at fatigue failure was observed by TEM and the correlation between changes in precipitates and low cycle fatigue failure is discussed.

\subsection{TEM Observation}

Figure 6 shows the microstructure of a specimen before the thermal fatigue testing. The wavy lines in Fig. 6 are dislocation lines occurring during the water quenching. No precipitates are observed in the specimen before the thermal fatigue tests.

Figures 7(a) (c) are examples of TEM observations of the fractured test pieces after the thermal fatigue tests No. 3, 7, and 8 in Table 2. The TEM micrograph were chosen to show the temperature dependence, which affects the stress-strain relation strongly during the fatigue test as shown in Fig. 2(a). Figure 7(a) shows the microstructure of the No.3 specimen $(\Delta \varepsilon= \pm 0.55 \%$, $\Delta \mathrm{T}=100 \sim 250^{\circ} \mathrm{C}, \Delta \mathrm{t}=10 \mathrm{~min}$.) with the picture of the diffraction pattern showing the g vector. 
There are precipitates and dislocations in Fig. 7 (a) (c), and the sizes and densities of the precipitates are affected by the test conditions, i.e., the size of the precipitates increases with the maximum temperature and the density is higher for lower temperatures. Two types of precipitates are observed in Fig. 7 (a) (c): one appears needle and the other ellipsoidal-like. The needle-like precipitates incline in the same direction at an angle to the g vector and are present on the $<100>$ plane. The chemical compositions of the two types of precipitates were the same, the intermetallic compound $\mathrm{Al}_{2} \mathrm{Cu}$. The needle-like precipitates are actually considered to be plane in shape [24], and their thicknesses appear in the micrographs as needle-like. In general, $\Theta$-phase ellipsoidal precipitates are considered to be contained in the precipitates, but they cannot be distinguished from the other precipitates in this observation of the surface. In this paper, to evaluate the relationships between the precipitates and fatigue failure the precipitates were simply divided into two types; needle-like (type 1) and ellipsoidal-like (type 2). To identify the two precipitates crystallography and morphology, the precipitates on other planes such as (101) and (001) planes should be observed. This observation remains as a further work.

The sizes of the two types of precipitates are defined as shown in Fig. 8, i.e. the length of the needle-like precipitate is defined as the size, $\mathrm{L}_{\text {type1 }}$, and the length of longer axis of the ellipsoidal-like precipitate, $\mathrm{L}_{\text {type2 }}$. The relationship between the size of the precipitates and fatigue life, and the plastic work density per unit time are discussed below. 


\subsection{Relationship between Size of Precipitates and Fatigue Life}

Figure 9(a) and (b) show the relationships between the mean sizes of type 1, and type 2

and fatigue life, where the lines connect the data plots with only one test parameter varied. For the

effect of the cycle period (chained lines: No. 3, 5, and 6), temperature range (solid lines: No. 3, 7, and 8), and strain amplitude (broken-lines: No. 3 and 4) in Fig. 9 (a), there are correlations between the mean size of type 1 and the cycle period, temperature range, and strain amplitude. Longer cycle period, higher temperature, and smaller strain amplitude lead to smaller mean size of type 1.

Moreover, the fatigue life is longer with smaller size of precipitates, and there are no type 1 precipitates if the fatigue life is longer than a certain time to fatigue failure. This indicates that the size of type 1 precipitate has a strong effect on the fatigue life, and that life is long when no type 1 precipitates are present in the microstructure.

For the type 2 precipitates in Fig. 9(b), the cycle period (chained lines: No. 3, 5, and 6) does not make a great difference in the mean size of precipitate. The effect of the temperature range (solid lines: No. 3, 7, and 8) on the mean size of the type 2 is largest. The effect of strain amplitude (broken-lines: No. 3 and 4) on the mean size of the type 2 is between those of the effect of temperature range and cycle period. Therefore, for type 2 precipitates, there is no correlation between the mean size and the fatigue life. All this suggests that the fatigue life can be lengthened by preventing the formation of type 1 precipitates or by reducing the size. 
The good correlation between the mean sizes of the type 1 precipitate and fatigue failure

comes from the interaction between the type 1 precipitates and dislocation. That is, the type 1

precipitate becomes obstacles for the progress of the dislocation and the dislocation piles up around

the type 1 precipitates. The lager mean size of the type 1 precipitate leads to the more pile-up of the dislocation.

\subsection{Relationship between Size of Precipitates and Plastic Work Density per unit time}

Figure 10 shows the relationship between the mean size and the plastic work density per unit time for types 1 and 2 precipitates. It can be seen from Fig. 10(a) that there is a correlation between the mean size of the type 1 and the plastic work density per unit time over $0.00175 \mathrm{~kW} / \mathrm{m}^{3}$, i.e., the plastic strain work density per unit time is larger as the mean size of type 1 is larger. The mean size of the type $1\left(\mathrm{~L}_{\mathrm{type} 1}\right)$ is expressed by a formula of plastic work density per unit time, except for the test 6 results, as follows:

$$
\mathrm{L}_{\text {type1 }}=1623.6 \cdot \ln \left(\Delta \mathrm{P}_{3}\right)+10111
$$

On the other hand, there is no correlation of the mean size of type 2 precipitate with the plastic work density per unit time In Fig. 10(b).

Equation (4) can be used to estimate the mean size of the type 1 if the plastic work density per unit time as a macroscopic characteristic is obtained from fatigue test results. However, Eq. (4) can be applied to the loading condition discussed in this paper. For the other loading conditions, 
which include hold time and creep deformation, additional experiments are required.

\section{CONCLUSIONS}

In this paper, a method to evaluate low cycle thermal fatigue failure was developed for the aluminum alloy AC2B-T6 which is used for cylinder heads of diesel engines. The relationship between low cycle thermal fatigue characteristics and microstructure observed by TEM is also discussed. The following conclusions were obtained:

1. Stress-strain relations are influenced by temperature range, cycle period, strain range, and mean strain. The effect of temperature range on the stress-strains is the largest.

2. Thermal fatigue life is influenced by temperature range, cycle period, strain range, and mean strain. The effect of the cycle period on the thermal fatigue life is the largest.

3. There is a correlation between the plastic work density per unit time and time to fatigue failure, irrespective of the temperature ranges, symmetric strain ranges, asymmetric strain ranges, cycle periods, and mean strain. Plastic work density per unit time was shown to provide a useful index for evaluating thermal fatigue under the condition of the time period of fatigue tests conducted in this paper.

4. Precipitates on the (100) plane were observed after the thermal fatigue tests. The precipitates were categorized into two types, needle-like type 1 and ellipsoidal-like type 2 on the (100) 
plane.

5. There is a strong positive correlation between the plastic work density per unit time and the mean size of Type 1 precipitates observed in the (100) plane. This means that the macroscopic characteristic of plastic work density per unit time can be used to know the condition of the microstructure of a specimen. This also suggests the possibility of developing method for evaluating the thermal fatigue life by considering the macroscopic and microscopic characteristics.

Finally it should be noted that additional experiments and microstructural observation will be needed to apply the method discussed in this paper to more general cases. These will appear in the other paper.

\section{ACKNOWLEDGEMENTS}

The authors wish to thank Professor Soumei Ohnuki (Graduate School of Material Science and Technology, Hokkaido University) for discussions and comments.

\section{REFERENCES}

[1] K. Sasaki, T. Takahashi and H. Numano,” Low Cycle Fatigue Failure and Microstructural Change of Aluminum Alloy Subjected to Thermo-Mechanical Loading”, ICM-8 proceedings, 
(1999) 79-84.

[2] T.S. Srivatsan, D. Kolar and P. Magnusen, "Influence of temperature on cyclic stress response strain resistance and fracture behavior of aluminum Alloy 2524”, Materials Science and Engineering, Vol. A314 (2001) 118-130.

[3] D. A. Clark and W. S. Johnsonl, ”Temperature effects on fatigue performance of cold expanded holes in 7050-T7451 aluminum alloy”, Fatigue International Journal of Fatigue, Vol. 25, (2003) 159-165.

[4] E.A. DeBartolo and B.M. Hillberry, "Effects of constituent particle clusters on fatigue behavior of 2024-T3 aluminum alloy”, Int. J. Fatigue Vol. 20, (1998) 727-735.

[5] Kun Yu, Wenxian Li, Songrui Li, Jun Zhao, ”Mechanical properties and microstructute of aluminum alloy 2618 with Al3(Sc, Zr) phases”, Materials Science And Engineering, Vol. A368, (2004) 88-93.

[6] T. Fujii, C. Watanabe, Y. Nomura, N. Tanaka and M. Kato, "Microstructural Evolution during Low Cycle Fatigue of a 3003 Aluminum Alloy”, Materials Science and Engineering, Vols. A319-321, (2001) 592 -596.

[7] S. C. Bergsma, M. E. Kassner, X. Li and M. A. Wall, "Strengthening in The New Aluminum Alloy AA 6069”, Materials Science and Engineering, Vol. A254, (1998) 112 -118.

[8] H. S. Turkmen, R. E. Loge, P. R. Dawson and M. P. Miller, "On The Mechanical Behavior of 
AA 7075-T6 during Cyclic Loading”, International Journal of Fatigue, Vol. 25, (2003) 267-281.

[9] J. Fan, D. L. McDowell, M. F. Horstemeyer and K. Gall, “Cyclic Plasticity at Pores and Inclusions in Cast Al-Si Alloys”, Engineering Fracture Mechanics, Vol. 70, (2003) 1281-1302.

[10] T.C. Tsai and J.C. Chang, Chuang TH, ”Atmospheric Stress Corrosion Cracking of Superplastic 7475 Aluminum Alloy”, Metallurgical and Materials Transactions A”, Vol. 27A, September, (1996) 2617-2627.

[11] S. Esmaeili, L.M. Cheng, A. Deschamps, D.J.Lloyd, W J Poole, “The deformation behaviour of AA6111 as a function of temperature and precipitation state”, Materials Science and Engineering, Vols. A319-321, (2001) 461 -465.

[12] D. Dumont, A. Deschamps, Y. Brechet, “On the relationship between microstructure strength and toughness in aa7050 aluminum alloy”, Materials Science and Engineering, Vol. A356, (2003) 326-336.

[13] T. Takahashi, A. Koike and K. Sasaki, "Inelastic Behavior and Low Cycle Fatigue of Aluminum Alloy Subjected to Thermo-Mechanical Loading”, SAE1998 Transactions, Vol.107, Journal of Materials \& Manufacturing, Section 5, (1998) 454-461.

[14] T. Takahashi, Y. Sugimura and K. Sasaki, “Thermal Plastic-Elastic Analysis in Consideration of Metallurgical Microstructure”, ASME, Journal of Manufacturing Science and Engineering, Vol. 126, (2004) 25-32. 
[15] Takashi Nagayoshi, Takao Kodaira, Masahiko Kumano, “Analysis of thermal fatigue cracks in cylinder head”, JSAE proceeding, Vol.21, (1992) 153-156.

[16] K.S.Lee, D.N. Assanis, J. Lee and K.M. Chun, “Measurement and Predictions of Steady-State and Transient Stress Distribution in a Diesel Engine Cylinder Head”, SAE proceedings, (1999) 1999-01-0973.

[17] L. F. Coffin, “A Study of the Effects of Cyclic Thermal Stresses on a Ductile Metal”, ASME, Vol. 76, (1954) 931-950.

[18] S. S. Manson, "Behavior of Materials under Conditions of Thermal stress”, NACA Report 1170, (1954).

[19] D. E. Martin, “An Energy Criterion for Low-Cycle Fatigue”, ASME, Journal of Basic Engineering, 82, (1961) 565-571.

[20] J. D. Morrow, “Cyclic Plastic Strain Energy and Fatigue of Metals”, ASTM STP 378, (1965) 45-87.

[21] F. Ellyin, and K. Golos, “Multiaxial Fatigue Damage Criterion”, ASME, Journal of Engineering Material and Technology, 110, (1988) 63-68.

[22] H. Ishikawa, K. Sasaki and K. Ohguchi, "Prediction of Fatigue Failure of 60Sn-40Pb Solder Using Constitutive Model for Cyclic Viscoplasticity”, ASME, Journal of Electronic Packaging, 118, (1996) 164-169. 
[23] J. H. L. Pang, B. S. Xiong and T. H. Low, “Low Cycle Fatigue Study of Lead Free 99.3Sn-0.7Cu Solder Alloy”, International Journal of Fatigue, 26, (2004) 865-872.

[24] J.Y. Yao, G.A. Edwards, D.A. Graham, “Precipitation and Age-Hardening in Al-Si-Cu-Mg-Fe Casting Alloys”, Materials Science Forum Vols.217-222, (1996) 777-782. 
Captions of tables and figures

Table 1 Chemical compositions, wt (\%)

Table 2 Thermo-mechanical fatigue test conditions with $\mathrm{N}_{\mathrm{f}}$ and $\mathrm{t}_{\mathrm{f}}$

Fig. 1 Strain and temperature versus time

Fig. 2 Stress-strain relation of the thermo-mechanical loading for different test factors

(a) Temperature range dependence

(b) Cycle period dependency

(c) Mean strain dependency

Fig. 3 Schematic representation of the plastic strain amplitude, stress amplitude, and plastic work density per unit time

Fig. 4 Plastic strain amplitude at the 3rd cycle versus time to fatigue failure

Fig. 5 Plastic work density per unit time at the 3rd cycle versus time to fatigue failure

Fig. 6 Microstructure of specimen before thermal fatigue tests

Fig. 7 Temperature range effect on microstructure

(a) No.3, $\pm 0.55 \%, 100-250^{\circ} \mathrm{C}, 10 \mathrm{~min} / \mathrm{cycle}$

(b) No.7, $\pm 0.55 \%, 120-300^{\circ} \mathrm{C}, 10 \mathrm{~min} /$ cycle

(c) No.8, $\pm 0.55 \%, 100-200^{\circ} \mathrm{C}, 10 \mathrm{~min} /$ cycle

Fig. 8 Precipitate types and shapes (schematic figure)

Fig. 9 Mean size of precipitate types versus time to fatigue failure

(a) Precipitate type 1

(b) Precipitate type 2

Fig. 10 Mean size of precipitate types versus plastic work density per unit time at 3rd cycle

(a) Precipitate type 1

(b) Precipitate type 2 
Table 1 and Table 2 (K. SASAKI and T. TAKAHASHI )

Table 1 Chemical compositions, wt (\%)

\begin{tabular}{c|c|c|c|c|c|c|c}
\hline $\mathrm{Cu}$ & $\mathrm{Si}$ & $\mathrm{Mg}$ & $\mathrm{Zn}$ & $\mathrm{Fe}$ & $\mathrm{Mn}$ & $\mathrm{Ni}$ & $\mathrm{Al}$ \\
\hline 2.94 & 6.09 & 0.31 & $<0.01$ & 0.17 & $<0.01$ & $<0.01$ & Balance \\
\hline
\end{tabular}

Table 2 Thermo-mechanical fatigue test conditions with $\mathrm{N}_{\mathrm{f}}$ and $\mathrm{t}_{\mathrm{f}}$

\begin{tabular}{|c|c|c|c|c|c|c|c|c|}
\hline \multirow{2}{*}{$\begin{array}{l}\text { Test } \\
\text { No. }\end{array}$} & \multicolumn{2}{|c|}{$\Delta \varepsilon$} & \multirow{2}{*}{$\begin{array}{l}(\%) \\
\text { Center }\end{array}$} & \multicolumn{2}{|c|}{$\Delta \mathrm{T}\left({ }^{\circ} \mathrm{C}\right)$} & \multirow{2}{*}{$\underset{(\mathrm{min})}{\Delta_{\mathrm{t}}}$} & \multirow{2}{*}{$\mathrm{N}_{\mathrm{f}}$} & \multirow{2}{*}{$\mathrm{t}_{\mathrm{f}}(\mathrm{sec})$} \\
\hline & $\varepsilon_{\max }$ & $\varepsilon_{\text {min }}$ & & $\mathrm{T}_{\text {max }}$ & $\mathrm{T}_{\min }$ & & & \\
\hline 1 & 0.4 & -0.4 & 0 & 250 & 100 & 10 & 984 & 590400 \\
\hline 2 & 0.5 & -0.5 & 0 & 250 & 100 & 10 & 586 & 351600 \\
\hline (3) & 0.55 & -0.55 & 0 & 250 & 100 & 10 & 221 & 132600 \\
\hline (4) & 0.6 & -0.6 & 0 & 250 & 100 & 10 & 24 & 14400 \\
\hline (5) & 0.55 & -0.55 & 0 & 250 & 100 & 5 & 18 & 5400 \\
\hline (6) & 0.55 & -0.55 & 0 & 250 & 100 & 20 & 858 & 1029600 \\
\hline (7) & 0.55 & -0.55 & 0 & 300 & 120 & 10 & 624 & 374400 \\
\hline (8) & 0.55 & -0.55 & 0 & 200 & 100 & 10 & 312 & 187200 \\
\hline$<9>$ & 0.4 & -0.7 & -0.15 & 250 & 100 & 10 & 131 & 78600 \\
\hline$<10>$ & 0.7 & -0.4 & 0.15 & 250 & 100 & 10 & 126 & 75600 \\
\hline$<11>$ & 0 & -1.1 & -0.55 & 250 & 100 & 10 & 99 & 59400 \\
\hline
\end{tabular}

( );TEM observation, $<>$;mean strain condition 
Figure 1 (K. SASAKI and T. TAKAHASHI)

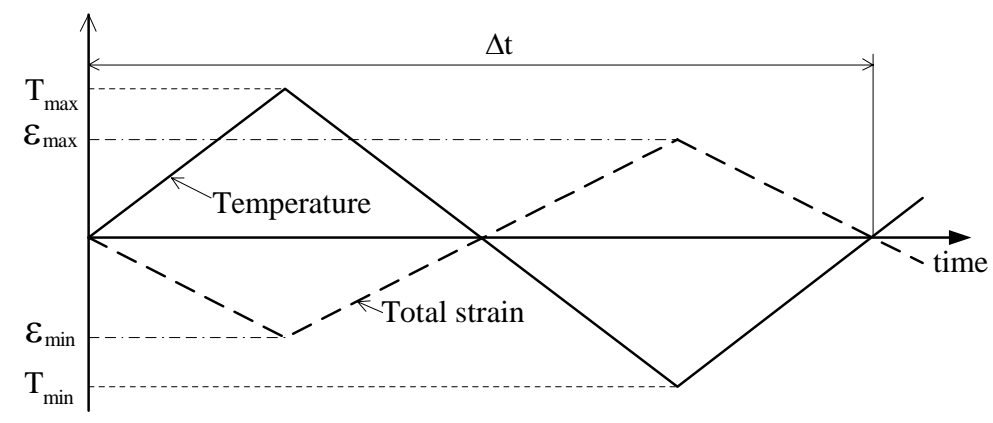

Fig.1 Strain and temperature versus time 
Figure 2 (K. SASAKI and T. TAKAHASHI)

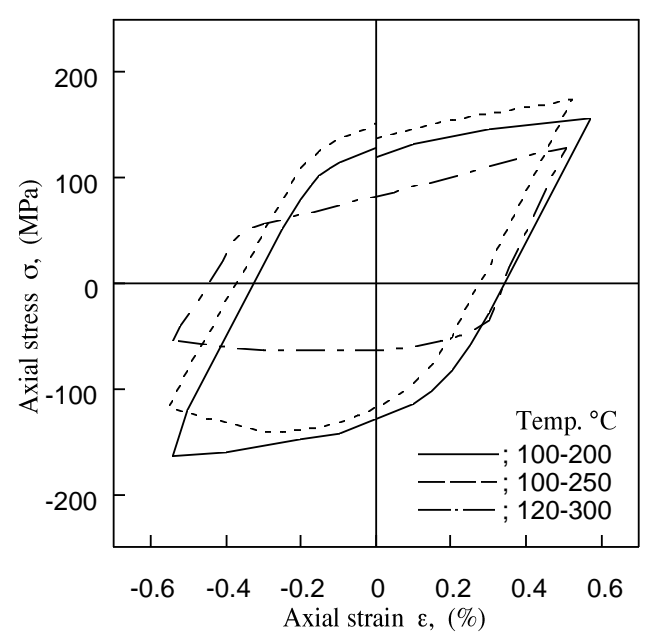

(a) Temperature range dependence

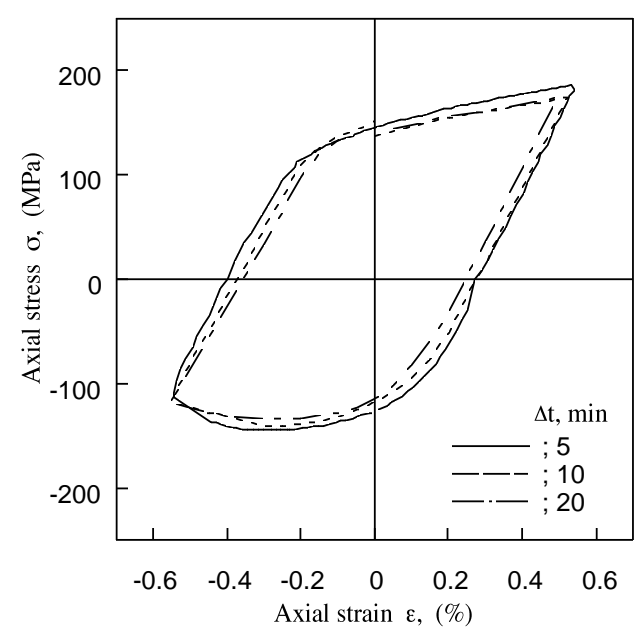

(b) Cycle period dependency

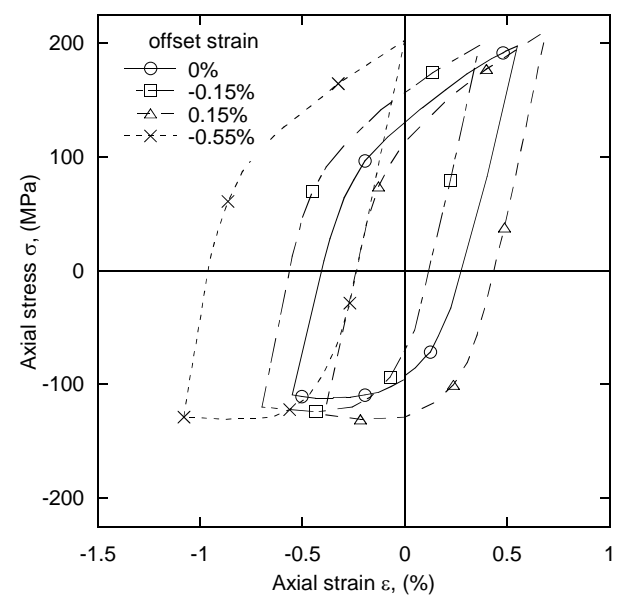

(c) Mean strain dependency

Fig. 2 Stress-strain relation of the thermo-mechanical loading for different test factors 
Figure 3 (K. SASAKI and T. TAKAHASHI)

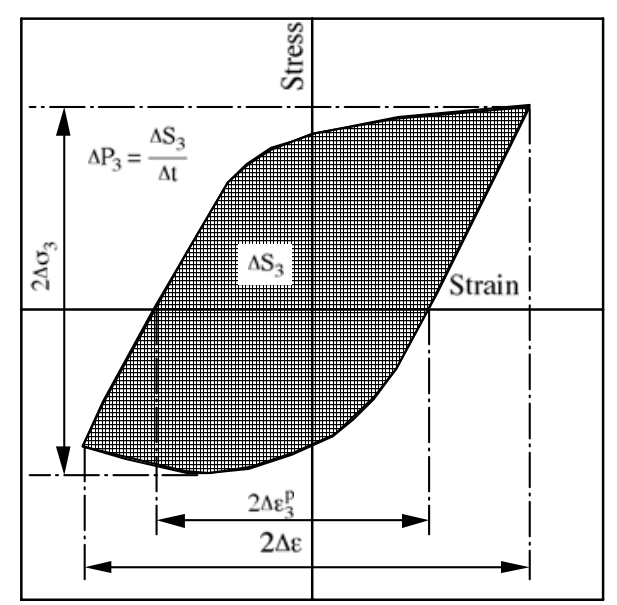

Fig.3 Schematic representation of the plastic strain amplitude, stress amplitude, and plastic work density per unit time 
Figure 4 and Figure 5 (K. SASAKI and T. TAKAHASHI)

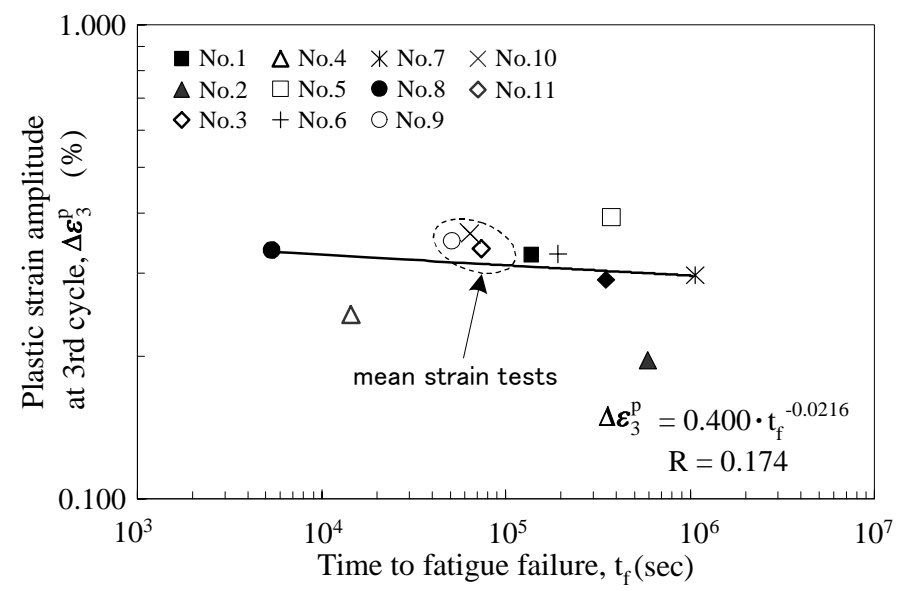

Fig.4 Plastic strain amplitude at the 3rd cycle versus time to fatigue failure

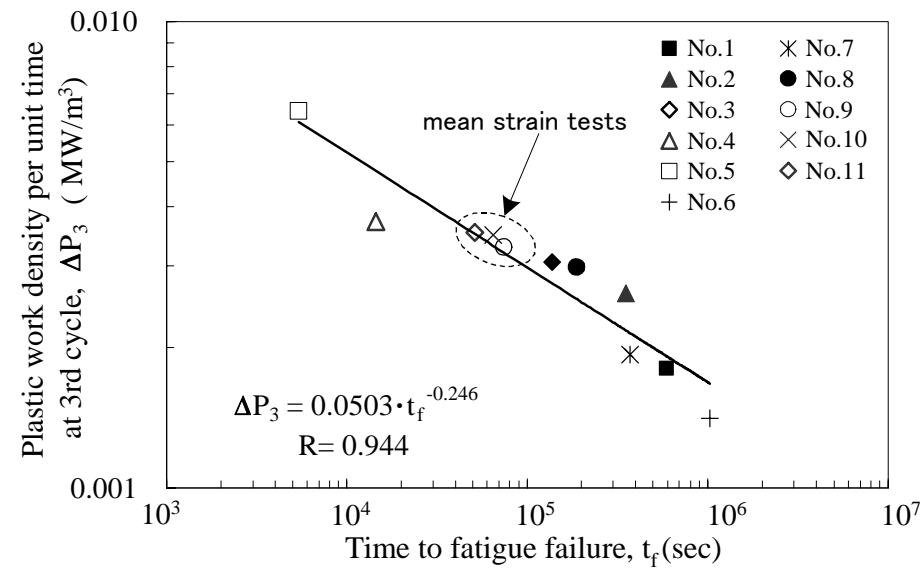

Fig.5 Plastic work density per unit time at the 3rd cycle versus time to fatigue failure 
Figure 6 (K. SASAKI and T. TAKAHASHI)

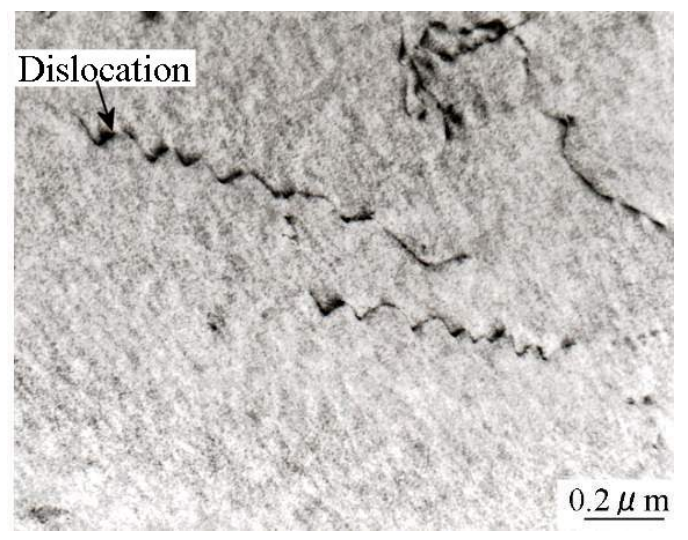

Fig.6 Microstructure of specimen before thermal fatigue tests 
Figure 7 (K. SASAKI and T. TAKAHASHI)
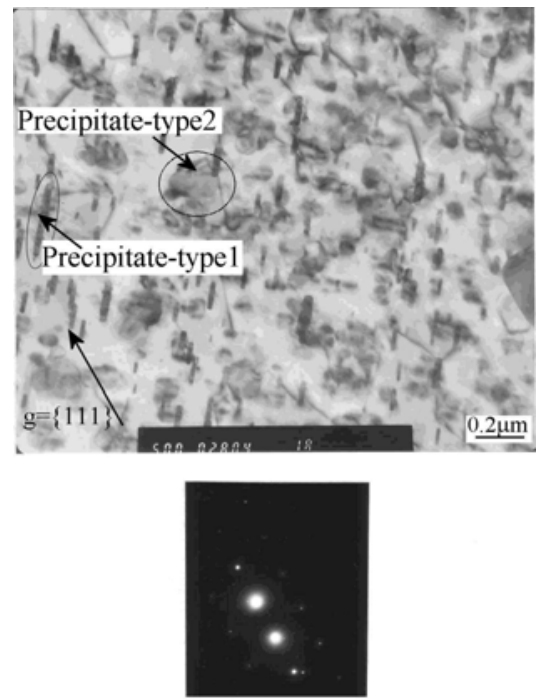

Diffraction pattern

(a) No.3, $\pm 0.55 \%, 100-250^{\circ} \mathrm{C}, 10 \mathrm{~min} / \mathrm{cycle}$

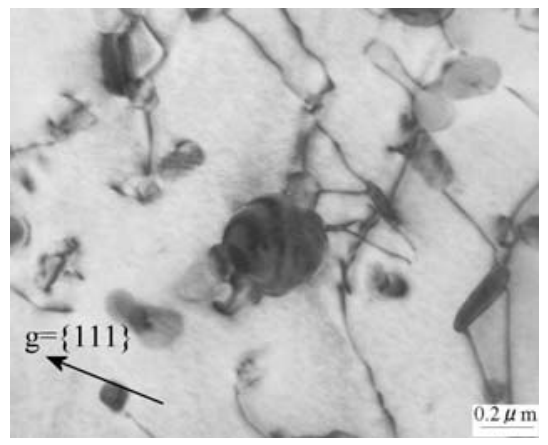

(b) No.7, $\pm 0.55 \%, 120-300^{\circ} \mathrm{C}, 10 \mathrm{~min} /$ cycle

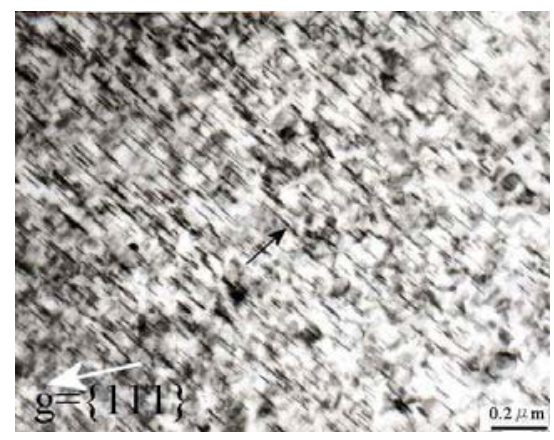

(c) No. $8, \pm 0.55 \%, 100-200^{\circ} \mathrm{C}, 10 \mathrm{~min} /$ cycle

Figure 7 Temperature range effect on microstructure 
Figure 8 (K. SASAKI and T. TAKAHASHI)

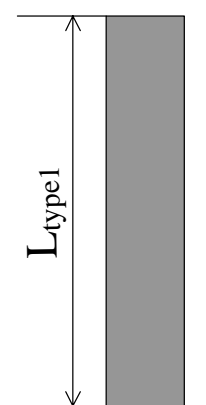

(a) Needle-like (Type 1)

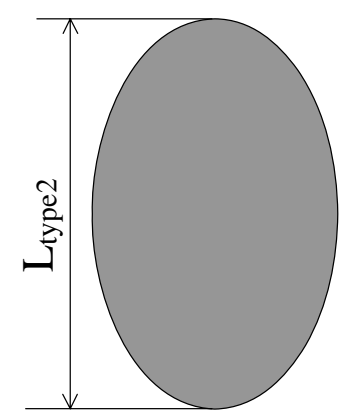

(b) Ellipsoidal-like (Type 2)

Fig.8 Precipitate types and shapes (schematic figure) 
Figure 9 (K. SASAKI and T. TAKAHASHI)

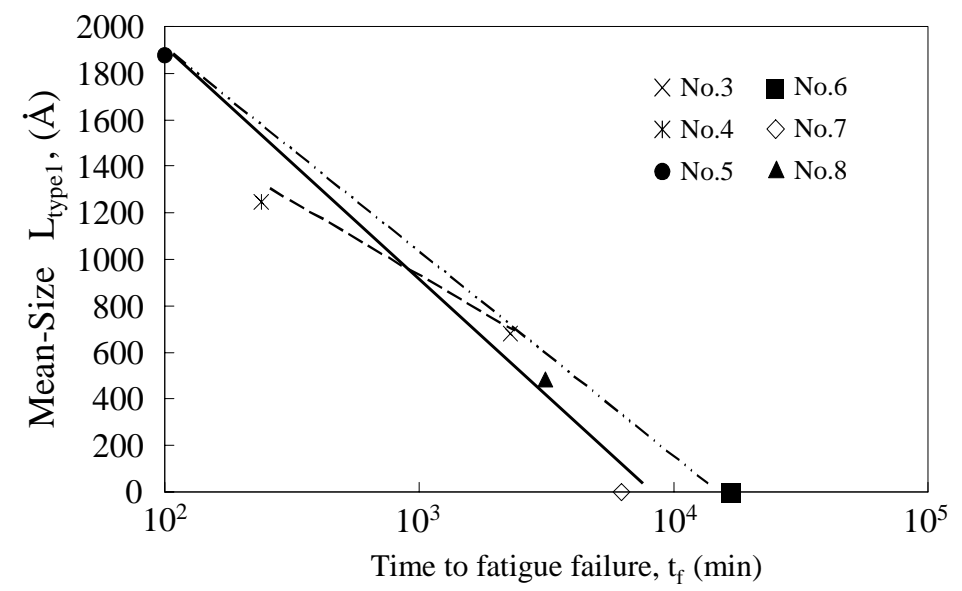

(a) Precipitate type 1

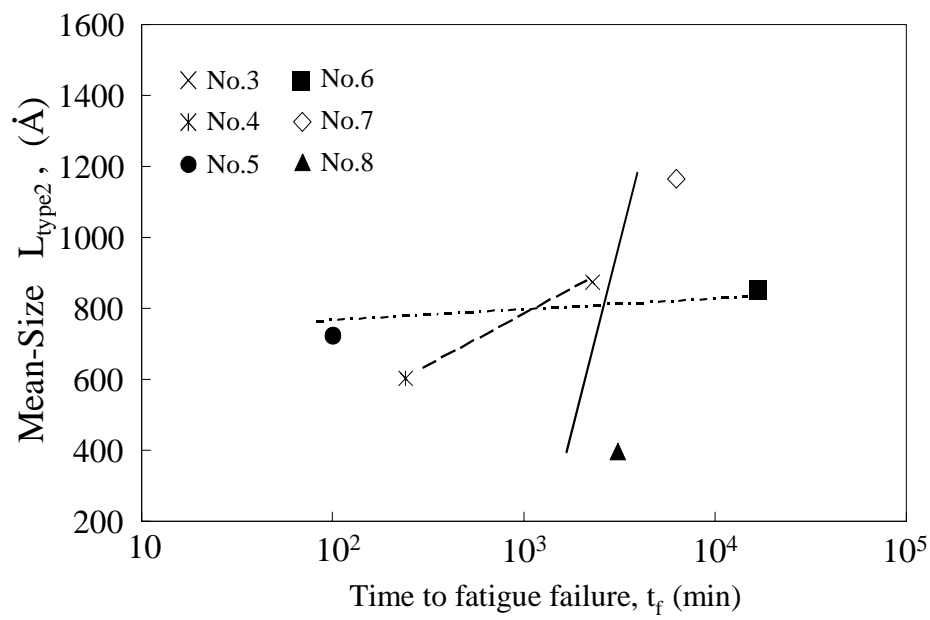

(b) Precipitate type 2

Fig. 9 Mean size of precipitate types versus time to fatigue failure 
Figure 10 (K. SASAKI and T. TAKAHASHI)

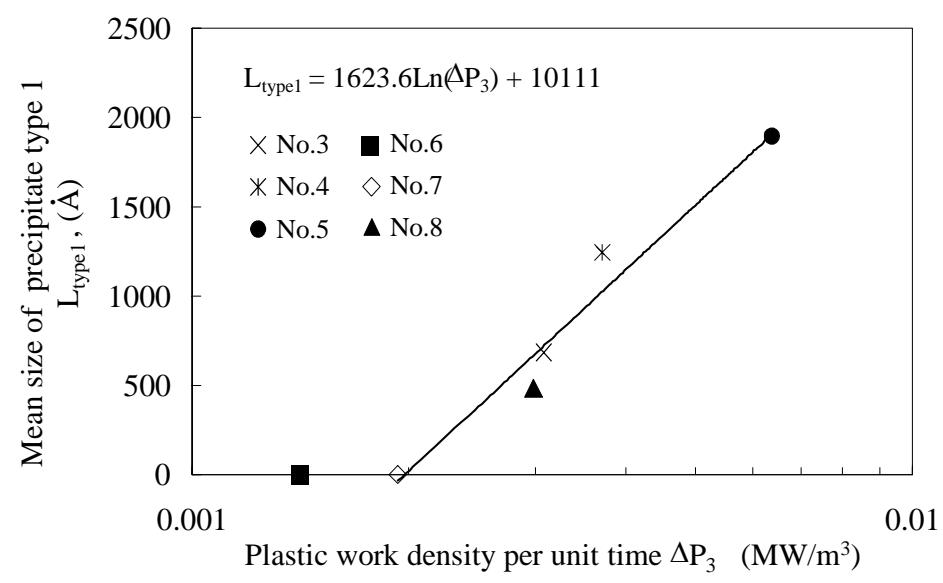

(a) Precipitate type 1

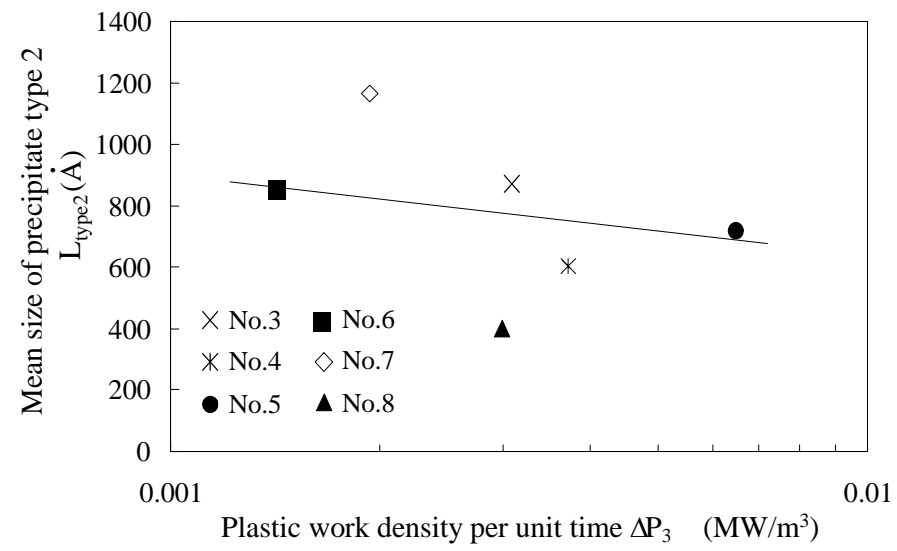

(b) Precipitate type 2

Fig. 10 Mean size of precipitate types versus plastic work density per unit time at 3rd cycle 